\title{
Direct evidence for transport of RNA from the mouse brain to the germline and offspring
}

\author{
Elizabeth A. O'Brien ${ }^{1}$, Kathleen S. Ensbey², Bryan W. Day', Paul A. Baldock,4,5 and Guy Barry ${ }^{1,6^{*}}$
}

\begin{abstract}
Background: The traditional concept that heritability occurs exclusively from the transfer of germline-restricted genetics is being challenged by the increasing accumulation of evidence confirming the existence of experiencedependent transgenerational inheritance. However, questions remain unanswered as to how heritable information can be passed from somatic cells. Previous studies have implicated the critical involvement of RNA in heritable transgenerational effects, and the high degree of mobility and genomic impact of RNAs in all organisms is an attractive model for the efficient transfer of genetic information.

Results: We hypothesized that RNA may be transported from a somatic tissue, in this case the brain, of an adult male mouse to the germline, and subsequently to embryos. To investigate this, we injected one hemisphere of the male mouse striatum with an AAV1/9 virus expressing human pre-MIR941 (MIR941). After 2, 8 and 16 weeks following injection, we used an LNA-based qPCR system to detect the presence of virus and human MIR941 in brain, peripheral tissues and embryos, from injected male mice mated with uninjected females. Virus was never detected outside of the brain. Verification of single bands of the correct size for MIR941 was performed using Sanger sequencing while quantitation demonstrated that a small percentage $(\sim 1-8 \%)$ of MIR941 is transported to the germline and to embryos in about a third of the cases.
\end{abstract}

Conclusions: We show that somatic RNA can be transported to the germline and passed on to embryos, thereby providing additional evidence of a role for RNA in somatic cell-derived intergenerational effects.

Keywords: Transgenerational inheritance, Somatic, RNA, Transmission

\section{Introduction}

Robust transgenerational inheritance has been observed in a diverse range of organisms, from protozoans and plants through to mammals [1-10]. These findings imply that a mechanism exists whereby experiencedependent information is transferred between somatic and germline tissues. Furthermore, multiple studies point to the potential existence of an RNA-mediated

\footnotetext{
* Correspondence: Guy.Barry@qimrberghofer.edu.au

'QIMR Berghofer Medical Research Institute, Herston, QLD 4006, Australia

${ }^{6}$ The School of Biomedical Sciences, The University of Queensland, Brisbane, QLD 4072, Australia

Full list of author information is available at the end of the article
}

mechanism as a system for transferring epigenetic information [11-13], via sperm [14-16] and potentially its stability across multiple generations [17]. The mode of transportation of RNAs may be via membrane-bound vesicles that are expelled from cells and contain an abundance of small RNAs [18-20], including miRNAs [21]. Long non-coding RNAs have also been indirectly postulated to be transferred to offspring due to experience-dependent alterations in the sperm [22-25]. We, therefore, postulated that somatically expressed RNAs may be transported to the germline allowing realtime heritability of somatic, experience-dependent alterations.

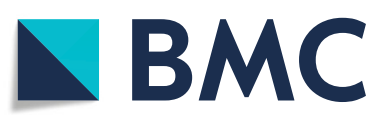

( ) The Author(s). 2020 Open Access This article is licensed under a Creative Commons Attribution 4.0 International License, which permits use, sharing, adaptation, distribution and reproduction in any medium or format, as long as you give appropriate credit to the original author(s) and the source, provide a link to the Creative Commons licence, and indicate if changes were made. The images or other third party material in this article are included in the article's Creative Commons licence, unless indicated otherwise in a credit line to the material. If material is not included in the article's Creative Commons licence and your intended use is not permitted by statutory regulation or exceeds the permitted use, you will need to obtain permission directly from the copyright holder. To view a copy of this licence, visit http://creativecommons.org/licenses/by/4.0/. The Creative Commons Public Domain Dedication waiver (http://creativecommons.org/publicdomain/zero/1.0/) applies to the data made available in this article, unless otherwise stated in a credit line to the data. 


\section{Results}

In order to test this hypothesis and trace genetic information from a somatic tissue to the germline in male mice, and to circumvent the issue of pervasive gene expression in sperm [26], we introduced a 72-bp RNA encompassing a pre-isoform of a human-specific microRNA (MIR) 941, pre-MIR941-1 [27], via an adeno-associated virus (AAV) gene delivery system (Additional file 1: Fig. S1), into one hemisphere of the mouse striatum using stereotactic injection. The AAV serotype 1/9 (AAV1/9) vector, a singlestranded DNA packaging virus, has been shown to infect both neurons and astrocytes [28, 29]. The AAV1 vector was designed to also produce a single-stranded DNA fragment of the rabbit $\beta$-globin gene which is used commercially for determining viral titre. We used this gene fragment to determine presence of the virus. Despite the fact that the AAV1 virus can be retrogradely transported via axons to the contralateral region [30] and the cerebellum [31], this system allowed us to restrict viral infection to the target site and to discrete regions of the mouse brain while then specifically monitoring potential transport of virally expressed pre-MIR941-1 outside of the brain using gene-specific PCR.

We initially sought to determine the specificity, reproducibility and detection limit using a locked nucleic acid (LNA) quantitative PCR (qPCR) system. Our methodological approach required a minimum length of the desired PCR product, hence the reason we targeted a 72-bp pre-isoform transcript of MIR941. Henceforth, we will use the term 'MIR941' to describe the pre-MIR941-
1 transcript. Using serial dilutions of positive control injection sites, qPCR reactions produced single bands of both MIR941 and rabbit $\beta$-globin as detected on an agarose gel (Additional file 2: Fig. S2). We found that we could detect MIR941 down to a 1:100 dilution (starting with $60 \mathrm{ng}$ RNA; Additional file 2: Fig. S2A) while the AAV1 virus could be detected down to a $\sim 1: 15,000$ dilution (starting with $60 \mathrm{ng}$ DNA; Additional file 2 Fig. S2B). We could not detect either MIR941 or rabbit $\beta$ globin fragment in control or mock-treated animals (Additional file 3: Fig. S3).

At 2 weeks post-injection, we found detectable MIR941 expression in the injection sites; however, no expression was detected in the contralateral site (Fig. 1; Additional file 4: Fig. S4). 'Positive' bands on a gel for all figures were supported by melt-curve analysis and melting temperatures (see Additional file 5: Supplementary Information). No expression was detected in the cerebellum or liver but, crucially, expression was detected in the lymph node and vas deferens and epididymis (V/E; Fig. 1; Additional files 4, 6: Figs. S4 and S5; Additional file 5: Supplementary Information). The epididymis and vas deferens contain matured sperm that are ready for ejaculation. For this reason, we took these tissues as opposed to the testis as they technically gave us very clean RNA from a source containing a high percentage of mature sperm.

The evidence of MIR941 in the V/E that contains mostly mature sperm, of the injected mice after 2 weeks prompted us to investigate whether this RNA may be

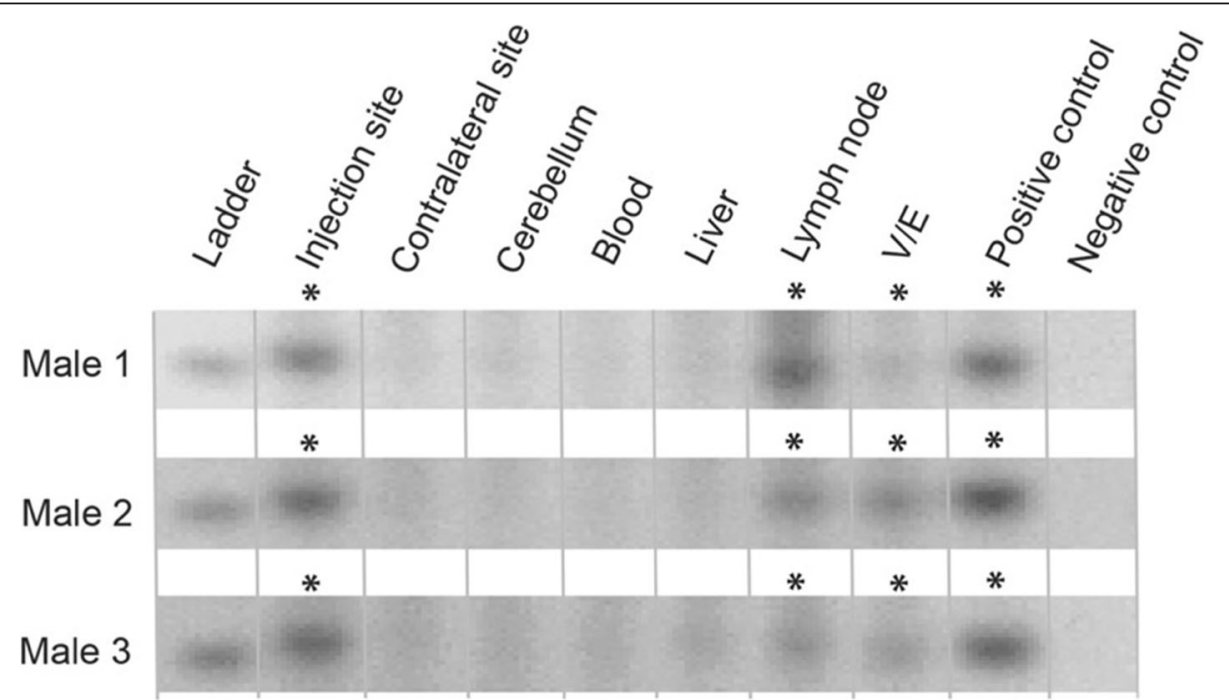

Fig. 1 Detection of human MIR941 following 2 weeks post AAV1 injection into the striatum of male mice. An AAV1 viral vector, encoding human pre-MIR941-1 (MIR941), was injected into a single striatal hemisphere of three male mice. Following sacrifice after 2 weeks post-injection, MIR941 was detected, using gene-specific locked nucleic acid (LNA) quantitative PCR (qPCR), in the injection site, lymph node and vas deferens/ epididymis (V/E). Human embryonic kidney (HEK) 293 cells were used as a positive control for MIR941 while a no template control served as a negative control. *Samples that were positive on the gel (single band of expected size) and were supported by melt-curve analysis (Additional file 5: Supplementary Information) 
transmitted to embryos. As a full cycle of spermatogenesis takes $\sim 5$ weeks in mice, we mated male mice, after 6-8 weeks post-injection, with wildtype female mice. This would serve to increase the probability that brainderived MIR941 had sufficient time to enter the testis and complete spermatogenesis. Male mice were sacrificed after 8 weeks and embryos were collected from wildtype female mice at 7.5 days post coitum (d.p.c.). Here we again detected MIR941 in samples from the injection and contralateral sites, cerebellum, lymph node and V/E (Fig. 2; Additional files 7, 8: Figs. S6, S7). Crucially, we additionally detected MIR941 in 9 of the 18 embryos screened that originated from males treated with AAV1/MIR941. Viral presence was restricted to brain samples (Fig. 2; Additional file 7: Fig. S6).

Although we could observe single bands of the correct size on the gels, we further validated all 'positive' bands using Sanger sequencing (Fig. 3a, b). Quantitative analysis, using UniSp6 as a spike-in control, showed that the amount of RNA found in the positive bands outside the brain were $\sim 1-2 \%$ of what is seen in the injection sites (Fig. 3c).

We postulated that although we could detect MIR941 in some of the embryos, extending the time after injection and before mating may increase the detectability of MIR941 in embryos. Hence, we waited until 14 weeks post-injection to begin mating treated males with wildtype females and sacrificed the males at 16 weeks postinjection. Here we observed 17 out 60 embryos that were indeed positive for MIR941 (Fig. 4; Additional file 9: Fig. S8). These animals also reflected our previous results where MIR941 was detected in the injection and contralateral sites, cerebellum, lymph node and V/E but not in whole blood and liver. Viral presence was again only observed in discrete brain regions (Fig. 4; Additional file 9: Fig. S8).

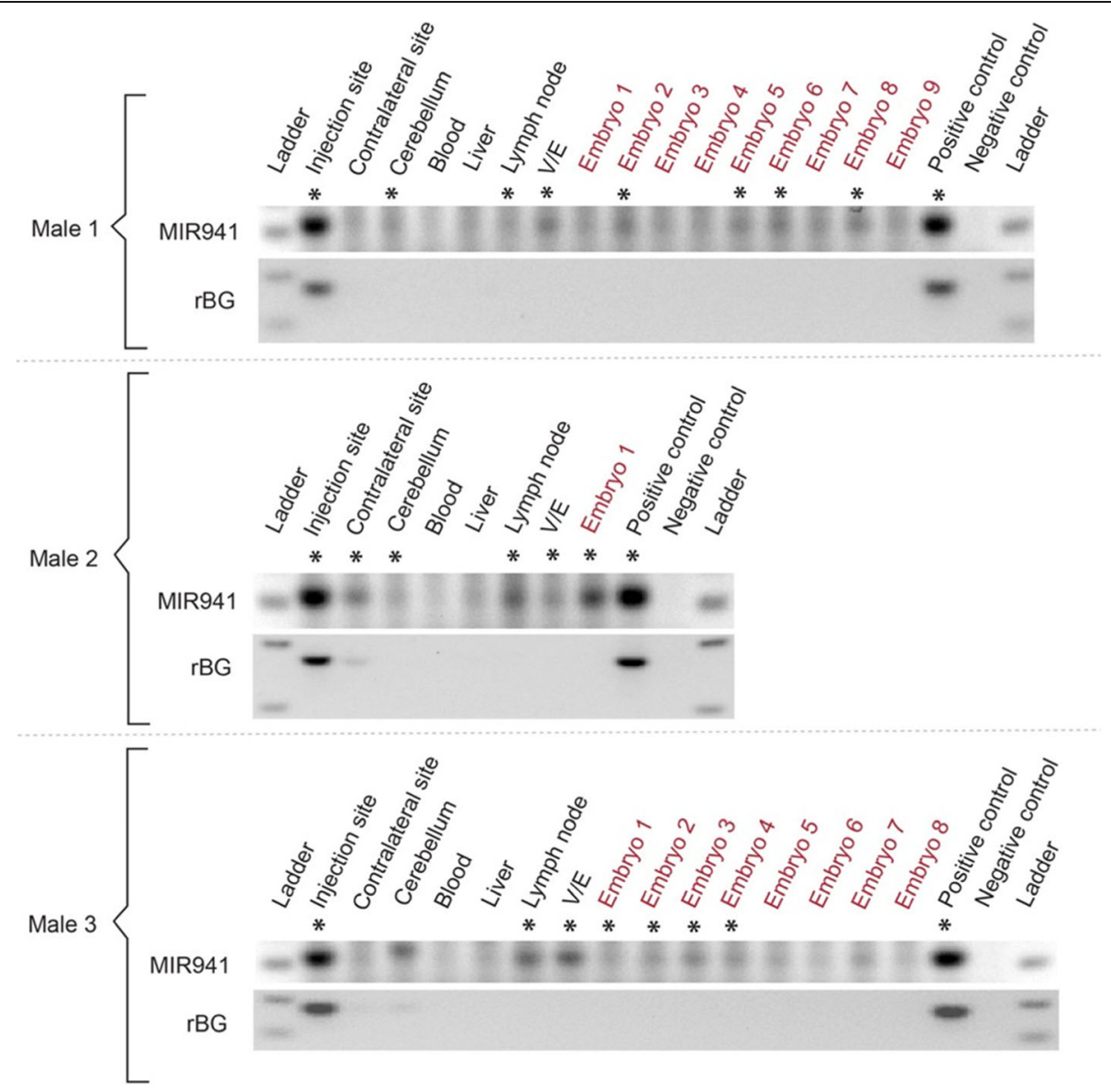

Fig. 2 Detection of human pre-MIR941-1 in mouse embryos. AAV1-encoded pre-MIR941-1 (MIR941) was injected into one striatal hemisphere of three male mice. After 8 weeks post-injection, MIR941 was detected in injection and contralateral sites, cerebellum, lymph node and vas deferens/ epididymis (V/E). Injected male mice were mated between 6 and 8 weeks following injection with wildtype female mice. Evidence of MIR941 was detected in 9 of the 18 embryos (7.5 d.p.c.) screened. Rabbit $\beta$-globin (rBG) fragment was only found in injection sites and one contralateral site. Positive control (HEK293), negative control (no template control). ${ }^{*}$ Samples that were positive on the gel and were supported by melt-curve analysis (Additional file 5: Supplementary Information) 

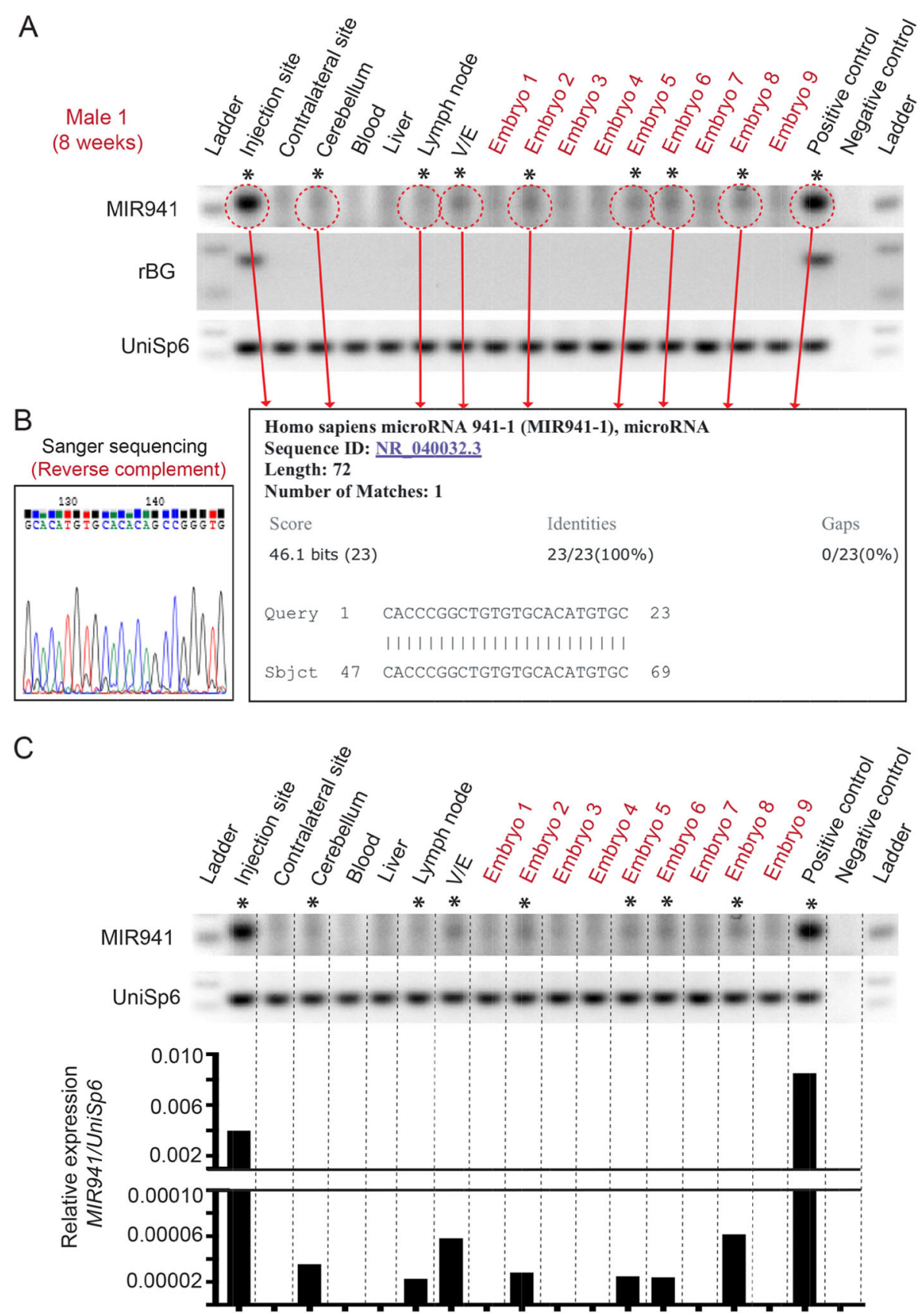

Fig. 3 Sequencing and quantitation of 'positive' MIR941 LNA qPCR bands. a, b For example, we show that for Male 1 (Fig. 2), all bands that were considered 'positive' for gel size and melt-curve analysis were also positive for human MIR941 following cloning and Sanger sequencing. c Quantitative analysis using UniSp6 spike-in controls demonstrate that the amount of MIR941 found to be positive outside of the brain is 1-2\% of what is seen in the striatal injection sites

Again, we further validated all 'positive' bands using Sanger sequencing (Fig. 5a, b). Quantitative analysis, using UniSp6 as a spike-in control, showed that the amount of RNA found in the positive bands outside the brain were $\sim 1-8 \%$ of what is seen in the injection sites (Fig. 5c). These figures were higher than for 8 weeks and may reflect more time allowed for collection in peripheral tissues and germline.

The persistent presence of MIR941 in the lymph node does suggest that the mode of transport may be in both the lymphatic and circulatory systems considering their closely associated capillary transport of nutrients and 

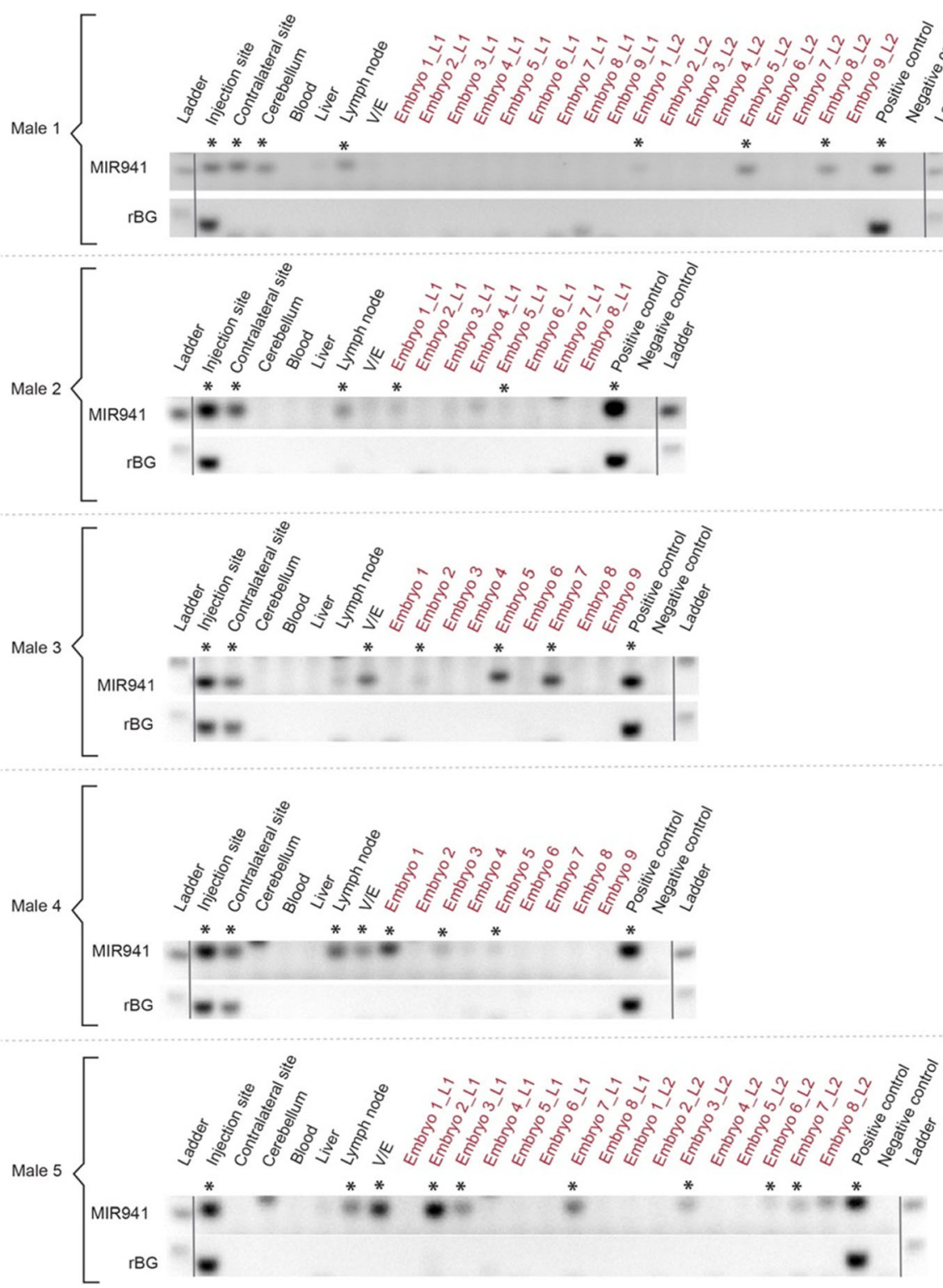

Fig. 4 Detection of human pre-MIR941-1 in mouse embryos. AAV1-encoded pre-MIR941-1 (MIR941) was injected into one striatal hemisphere of five male mice. After 16 weeks post-injection, MIR941 was detected in injection and contralateral sites, cerebellum, lymph node and vas deferens/ epididymis (V/E). Injected male mice were mated between 14 and 16 weeks post-injection with wildtype female mice and evidence of MIR941 was detected in 17 of the 60 embryos (7.5 d.p.c) screened. Rabbit $\beta$-globin (rBG) fragment was only found in injection and contralateral sites. Positive control (HEK293), negative control (no template control). *Samples that were positive on the gel and were supported by melt-curve analysis

small vesicles. We reasoned that MIR941 would be required to be contained in a vesicle so that degradation does not occur during transport, and vesicles are shared between the blood and the lymph due to their smaller size. However, whole blood, as opposed to the lymph node which collects lymph over a longer timeframe, may not be a suitable sample to detect what would be a very small amount of MIR941 at any one point, as blood flows faster than lymph. Therefore, in order to investigate whether MIR941 is present in the blood of the treated male mice, we used a series of microcentrifuge and ultracentrifuge spins to isolate the fraction of whole blood that contains vesicles. We were not successful in detecting MIR941 in both the 2- or 8-week samples and only detected the presence of the miRNA in one of the 16-week samples in the ultracentrifuge fraction that is presumed to contain the highest concentration of vesicles (Additional file 10: Fig. S9A, B). No presence of the virus was found in any of these samples (Additional file 10: Fig. S9C). 

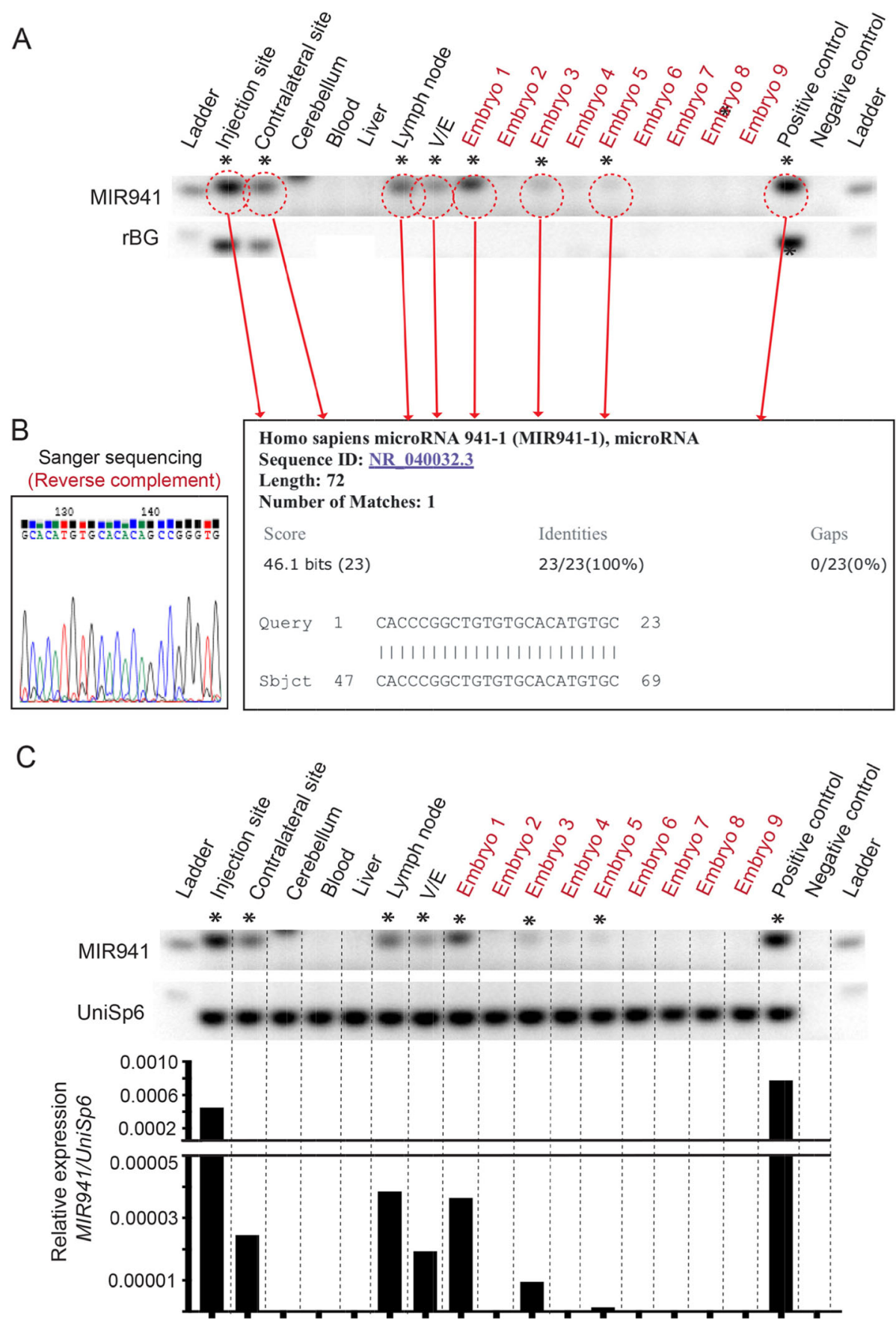

Fig. 5 Sequencing and quantitation of 'positive' MIR941 LNA qPCR bands. a, b For example, we show that for Male 4 (Fig. 4), all bands that were considered 'positive' for gel size and melt-curve analysis were also positive for human MIR941 following cloning and Sanger sequencing. c Quantitative analysis using UniSp6 spike-in controls demonstrate that the amount of MIR941 found to be positive outside of the brain is 1-8\% of what is seen in the striatal injection sites

\section{Discussion}

Our data indicate that RNAs may be physically transmitted from a somatic tissue in male mice, in this case the brain, to the germline and to subsequent embryos. The mode of transport for the RNA via the lymph and bloodstream is likely to be vesicles, which would provide a secure environment to avoid degradation and increase stability [32, 33]. Although we could only find one case where our detection system captured the RNA in the vesicle-containing fractions of ultracentrifuged whole blood (Additional file 10: Fig. S9), this may serve to only highlight current detection limitations. Therefore, we are 
unable to confirm the exact occurrence because we may not be capturing all positive samples, since our experimental design purposely imposed a low level of viral infection so as not to flood the endogenous system. However, combined data from both 8 and 16 week postinjected males and their respective embryos still showed a 33\% heritability rate. Furthermore, our thorough verification and quantitation of positive qPCR results from multiple animals and timeframes, combined with ensuring that the virus does not escape the brain, leads us to confidently conclude that this process does indeed occur at least in the mouse. We did find a trend towards overall higher expression in the injection sites in the brain (at 8 weeks) and higher heritability rates ( 8 weeks $-50 \%$, 16 weeks-28\%; Additional file 11: Fig. S10) although this is merely a correlation at this stage. Our study was limited in that we used only one model system and one small RNA. Future experiments should investigate RNAs of different sizes and sequences, coupled with alternate detection systems such as deep sequencing and in situ hybridization. However, if our results are verified in subsequent studies, the demonstration that a third of embryos contain the MIR941 transcript after 8 and 16 weeks post-injection would suggest that RNA transfer reflects a meaningful mechanism for intergenerational epigenetic effects and sets the foundation for direct measurements of the extent of RNA-based somatic inheritance in different species.

\section{Conclusion}

Our results provide evidence for a possible role of mobile RNA in the transmission of somatically derived epigenetic intergenerational effects.

\section{Materials and methods \\ AAV vector}

The plasmid preparation and viral vector production was performed at Penn Vector Core, University of Pennsylvania. The plasmid vector, pENN.AAV.CB7.CI.MIR941.rBG, was generated by inserting pre-MIR941-1 (Sequence: TGTGGA CATGTGCCCAGGGCCCGGGACAGCGCCACGGAAG AGGACGCACCCGGCTGTGTGCACATGTGCCCA) into the cloning plasmid pAAV.CB7.rBG. Briefly, the CB7 promoter-composed of CMV enhancer, beta-actin promoter and a chimeric intron-drives the expression of the pre-MIR941-1 transcript. The viral vector derived from the plasmid, AAV1.CB7.CI.MIR941.rBG, was produced, titred and supplied in PBS containing 0.001\% Pluronic F68. The average titre is $1.55 \times 10 \mathrm{e}^{13} \mathrm{GC} / \mathrm{ml}$.

\section{Animals}

All animal procedures were approved by the QIMRB Animal Ethics committee, ethics \#A1612-622 M. C57BL/
$6 \mathrm{~J}$ (Jax code 000664) were obtained from Animal Resource Centre (Canning Vale).

\section{Brain injections}

Male C57BL/6J aged 6-7 weeks were administered analgesia (Meloxicam $5 \mathrm{mg} / \mathrm{kg}$ ) $30 \mathrm{~min}$ prior to surgery. Animals were anaesthetized using inhaled isoflurane (2\%) and once anaesthetized were transferred onto the stereotactic device with nose cone attachment for continuous isoflurane administration. Once the mouse was adequately anaesthetized by evidence of pedal withdrawal reflex, the animal's head was clipped and disinfected using an alcohol swab, the skin was incised and a 2-mm drill hole was made and a solution (1-2 $\mu \mathrm{l})$ containing AAV vector was injected (Hamilton syringe) into the lateral portion of the striatum. Injections were made over a period of $3 \mathrm{~min}$ to ensure optimal parenchymal compliance. The micro-injector needle was retracted, the bur hole was plugged with bone wax, a 'splash block' of Bupivacaine $(5 \mathrm{mg} / \mathrm{kg})$ was applied to the skull/periosteum and the skin closed with tissue adhesive (VetBond). Animals were returned to their cages, given free access to food and water and monitored daily for any signs of neurological dysfunction. On the day following surgery, the animals were administered another dose of analgesia (Meloxicam $5 \mathrm{mg} / \mathrm{kg}$ ).

\section{Timed matings}

Wildtype C57BL/6J females aged 6-8 weeks were set up overnight with a male. The following morning, presence of a vaginal plug assumed that mating/fertilization occurred. We determine that embryos at this stage are aged 0.5 days post coitum (d.p.c).

\section{Collection of embryos}

Post implantation embryos at 7.5 d.p.c were collected from euthanized pregnant females. The uterine horn was dissected out and placed in ice-cold PBS. The embryos were separated by cutting between implantation sites along the uterine horn. The surrounding muscle layer is peeled back to expose the decidua. Individual embryos still encased in decidua tissue were flash frozen on dry ice and stored at $-80^{\circ} \mathrm{C}$ until homogenization for nucleic acid extraction.

\section{Dissection for tissue collection}

For tissue collection, animals were anaesthetized and then cardiac puncture was performed. Once blood was collected, cervical dislocation was performed. The following tissues were collected: injection site (striatum), contralateral striatum, cerebellum, inguinal lymph nodes, liver, vas deferens and epididymis (V/E). Dissected tissue was collected into Eppendorf tubes and flash frozen on 
dry ice. Storage was set at $-80^{\circ} \mathrm{C}$ prior to nucleic acid extraction.

\section{Blood and plasma samples}

Immediately after collection of blood, $0.1 \mathrm{ml}$ of blood was diluted in $0.15 \mathrm{ml}$ nuclease-free water (Invitrogen \#10977015) and $0.75 \mathrm{ml}$ TRIzol LS Reagent (Thermo Fisher \#10296010) was added. Samples were immediately flash frozen on dry ice and stored at $-80^{\circ} \mathrm{C}$ prior to nucleic acid extraction.

The remaining blood collected from cardiac puncture was placed in MiniCollect K2E K2EDTA $0.5 \mathrm{ml}$ (Greiner Bio-One \#450480). Manufacturer's instructions were followed to collect the resulting plasma. Plasma was stored at $-80^{\circ} \mathrm{C}$.

\section{Ultracentrifugation of plasma samples}

Plasma samples were thawed on ice. Three successive centrifugation steps were performed. The pellet at each step was collected and resuspended in TRIzol Reagent (Thermo Fisher \#15596026), while the supernatant was centrifuged again. The first centrifugation step was performed at $3000 \times g$ for $10 \mathrm{~min}$ at $4{ }^{\circ} \mathrm{C}$. The second centrifugation step performed was $12,000 \times g$ for $45 \mathrm{~min}$ at $4{ }^{\circ} \mathrm{C}$. The final centrifugation step performed was $110,000 \times g$ for $70 \mathrm{~min}$ at $4{ }^{\circ} \mathrm{C}$ in a Hitachi Micro Ultracentrifuge CS150NX. Samples were immediately flash frozen on dry ice and stored at $-80^{\circ} \mathrm{C}$ prior to nucleic acid extraction.

\section{Homogenization of tissue samples}

Tissue samples were transferred while still frozen into screw-capped tubes containing approximately 8-10 1.4$\mathrm{mm}$ zirconium oxide beads (Bertin Technologies KT03961-1-103.BK). Samples had appropriate amounts of TRIzol Reagent (Thermo Fisher \#15596026) added as per manufacturer's instructions. Samples were homogenized in Precellys 24 (Thermo Fisher) twice at $6000 \mathrm{rpm}$ for $30 \mathrm{~s}$ with a hold period in between. The homogenized sample was transferred into an Eppendorf tube to remove the beads. The samples were then centrifuged $12,000 \times g$ for $5 \mathrm{~min}$ at $4{ }^{\circ} \mathrm{C}$. The supernatant was collected in a new Eppendorf tube. Samples were stored at $-80^{\circ} \mathrm{C}$ prior to nucleic acid extraction.

\section{Extraction of nucleic acids (RNA and DNA)}

RNA and DNA were extracted from each sample. All samples had appropriate amounts of chloroform added to the TRIzol Reagent/TRIzol LS Reagent as per manufacturer's instructions. The aqueous layer that formed after centrifugation at $12,000 \times g$ for $15 \mathrm{~min}$ at $4{ }^{\circ} \mathrm{C}$ was collected and combined with $1.5 \times$ volume $100 \%$ ethanol. Purification of microRNA and total RNA from this fraction was performed using miRNeasy Mini/Micro Kit
(Qiagen \#217004/\#217,084) as per manufacturer's instructions. On-column DNase digestion was performed using the RNase-Free DNase Set (Qiagen \#79254).

After the aqueous phase was collected for extraction of RNA, the remaining interphase and phenol chloroform phase was used to extract DNA with the addition of Back Extraction Buffer (BEB - $4 \mathrm{M}$ guanidine thiocyanate, $50 \mathrm{mM}$ sodium citrate, $1 \mathrm{M}$ Tris), $0.25 \mathrm{ml} \mathrm{BEB}$ per $0.5 \mathrm{ml}$ TRIzol. The solution was shaken vigorously for $15 \mathrm{~s}$, incubated at room temperature for $10 \mathrm{~min}$ and then centrifugated at $12,000 \times g$ for $15 \mathrm{~min}$ at $4{ }^{\circ} \mathrm{C}$. The resulting aqueous layer was collected, mixed with $1 \times$ volume of $100 \%$ ethanol, and the DNA was purified using DNeasy Blood \& Tissue Kit (Qiagen \#69506) as per manufacturer's instructions.

RNA/DNA was quantified using NanoDrop Lite (Thermo Fisher).

\section{cDNA synthesis}

cDNA synthesis using the miRCURY LNA miRNA PCR Starter Kit (Qiagen \#3390320) was performed as per manufacturer's instructions. One first-strand cDNA synthesis reaction per sample was performed. Two hundred nanogrammes total RNA per $10 \mu \mathrm{l}$ cDNA synthesis reaction was performed for all samples except for plasma samples where $10 \mathrm{ng}$ total RNA per $10 \mu \mathrm{l}$ cDNA synthesis reaction was used. Each reaction included UniSp6 spike-in control. Protocol as per manufacturer's instructions was followed.

\section{Real-time PCR amplification with LNA-enhanced primers}

Real-time PCR was performed using components from miRCURY LNA miRNA PCR Starter Kit. All runs were performed using the QuantStudio5 Real-Time PCR System (Applied Biosystems) in 'fast' mode using ROX as the passive reference dye. Each reaction had a total volume of $10 \mu \mathrm{l}$.

\section{hsa-MIR-941 miRCURY LNA miRNA PCR assay}

This was a pre-designed, validated assay to target hsaMIR-941 (Qiagen product\# 339306, catalogue\# YP00204574). Each $10 \mu \mathrm{l}$ reaction was made up of the following: $5 \mu \mathrm{l} 2 \times$ miRCURY SYBR Green Master Mix, $0.05 \mu$ l ROX Reference Dye, $1.95 \mu$ l PCR primer mix, $3 \mu \mathrm{l}$ of cDNA template (diluted 1:10). The PCR was initially heat activated at $95^{\circ} \mathrm{C}$ for $2 \mathrm{~min}$, followed by 40 cycles of denaturation $\left(95^{\circ} \mathrm{C}\right.$ for $\left.10 \mathrm{~s}\right)$ and combined annealing/ extension $\left(60^{\circ} \mathrm{C}\right.$ for $\left.60 \mathrm{~s}\right)$.

\section{UniSp6 miRCURY LNA miRNA PCR assay}

This was a pre-designed, validated assay to target UniSp6 (Qiagen product\# 339306, catalogue\# YP00203954) which is a cDNA synthesis/PCR control. Each $10 \mu \mathrm{l}$ reaction was made up of the following: $5 \mu \mathrm{l} 2 \times$ miRCURY SYBR Green 
Master Mix, $0.05 \mu \mathrm{l}$ ROX Reference Dye, $1 \mu \mathrm{l}$ PCR primer mix, $0.95 \mu \mathrm{l}$ nuclease-free water, $3 \mu \mathrm{l}$ of cDNA template (diluted 1:60). The reaction was initially heat activated at $95^{\circ} \mathrm{C}$ for $2 \mathrm{~min}$, followed by 40 cycles of denaturation $\left(95^{\circ} \mathrm{C}\right.$ for $\left.10 \mathrm{~s}\right)$ and combined annealing/extension $\left(60^{\circ} \mathrm{C}\right.$ for 60 s). All reactions were positive for UniSp6.

\section{Rabbit $\beta$-Globin qPCR}

Custom qPCR LNA primers were designed through Exiqon prior to Qiagen's acquisition of the company. They were designed to target rabbit $\beta$-globin poly A tail in the virus. Each $10 \mu \mathrm{l}$ reaction was made up of the following: $5 \mu \mathrm{l} 2 \times$ miRCURY SYBR Green Master Mix, $0.05 \mu \mathrm{l}$ ROX Reference Dye, $1 \mu \mathrm{l}$ PCR primer mix, $0.95 \mu \mathrm{l}$ nuclease-free water, $3 \mu \mathrm{l}$ of DNA template $(1 \mathrm{ng} / \lambda)$. The reaction was initially heat activated at $95^{\circ} \mathrm{C}$ for $2 \mathrm{~min}$, followed by 35 cycles of denaturation $\left(95^{\circ} \mathrm{C}\right.$ for $\left.10 \mathrm{~s}\right)$ and combined annealing/extension $\left(60^{\circ} \mathrm{C}\right.$ for $\left.60 \mathrm{~s}\right)$.

Primers sequences: Forward-TATGGGGACATCATGAAGC; Reverse-CCAACACACTATTGCAATGA.

\section{Gels}

qPCR products were run on 3\% TAE agarose gels containing 1× Biotium GelRed NA Stain (Fisher Biotech \#41003) at $100 \mathrm{~V}$ for $90 \mathrm{~min}$ prior to imaging/image capture.

\section{Cloning and sequencing of $\mathrm{QPCR}$ product}

qPCR for hsa-miR-941 was performed as per the conditions outlined above. Samples were determined to be positive based on $\mathrm{Ct}$ value and melt-curve analysis. These positive $\mathrm{qPCR}$ products were purified using a MinElute PCR Purification Kit (Qiagen \#28004) as per manufacturer's instructions. A $20 \mu \mathrm{l}$ ligation reaction was set up which contained $9 \mu \mathrm{l}$ of purified insert, $1 \mu \mathrm{l}$ (25 ng) pCR2.1 linearized vector (Thermo Fisher \#K202020), $2 \mu \mathrm{l}$ of 10× T4 DNA Ligase Buffer (New England Biolabs \# M0202S), 1ul (400Units) of T4 DNA Ligase (New England Biolabs \# M0202S) and $7 \mu \mathrm{l}$ nuclease-free water. The reaction was conducted at $16^{\circ} \mathrm{C}$ for $16 \mathrm{~h}$. Transformation reactions were set up using $5 \mu \mathrm{l}$ of ligation reaction and $50 \mu \mathrm{l}$ chemically competent E. coli cells (New England Biolabs \# C3040I) and performed as per manufacturer's instructions. Forty microliters of $20 \mathrm{mg} / \mathrm{mL} \mathrm{X-gal} \mathrm{(5-bromo-4-chloro-3-indo-}$ lyl- $\beta$-D-galacto-pyranoside - Sigma Aldrich B44252) and $40 \mu \mathrm{l}$ of $100 \mathrm{mM}$ IPTG (isopropyl $\beta$-D-1-thiogalactopyranoside - AppliChem A4773) were mixed 1:1 prior to plating on the surface LB Agar plates containing $100 \mu \mathrm{g} / \mathrm{ml}$ ampicillin (Sigma Aldrich \#A9518) and this was allowed to dry prior to the transformation reaction being plated. The plates were incubated $30^{\circ} \mathrm{C}$ overnight, and the following day, white colonies were selected for further analysis. Each white colony was picked and inoculated into $3 \mathrm{~mL}$ LB broth containing $100 \mu \mathrm{g} / \mathrm{mL}$ ampicillin (Sigma Aldrich \#A9518). These liquid cultures were grown at $30^{\circ} \mathrm{C}$ with shaking $(250 \mathrm{rpm})$ for $20 \mathrm{~h}$. The cultures then had the DNA extracted from them using the QIAprep Spin Miniprep Kit (Qiagen \#27104) and the resulting DNA was quantified using NanoDrop Lite (Thermo Fisher). For sequencing using the BigDye Terminator v3.1 Cycle Sequencing Kit (Thermo Fisher), $150 \mathrm{ng}$ of vector and $3 \mathrm{pmol}$ of primer (M13F) were used per reaction as per manufacturer's instructions. The reaction was cleaned up and run on the 3130xl Genetic Analyzer (Thermo Fisher). The resulting sequence was used as input for BLAST to confirm insert identity.

\section{Supplementary information}

Supplementary information accompanies this paper at https://doi.org/10. 1186/s12915-020-00780-w.

Additional file 1: Figure S1. pENN.AAV.CB7.CI.MIR941.rBG. Plasmid produced for viral vector production by Penn Vector Core.

Additional file 2: Figure S2. Detection of (A) MIR941 and (B) a rabbit $\beta$-globin fragment in treated adult male mice. Positive control striatal injection sites from adult male mice were used to detect single bands using a gene-specific locked nucleic acid (LNA) quantitative PCR (qPCR) system.

Additional file 3: Figure S3. No detection of MIR941 or rabbit $\beta$-globin fragment in control (uninjected) or mock-treated (saline-injected) animals at either (A) 8 weeks or (B) 16 weeks post-injection. Additionally, no presence of rabbit $\beta$-globin fragment was found in control embryos, collected from 3 separate litters, from uninjected parents (C); positive control 1MDA cells, positive control 2 - HEK cells; negative control - no template control).

Additional file 4: Figure S4. Full size, unedited gels used for Fig. 1 in the main text.

Additional file 5. Supplementary Information.

Additional file 6: Figure S5. Representative full panel of melt curves for Week 2, Male 1 showing MIR941 LNA qPCR. Positive (black writing) and negative (red writing) melt curves and associated melting temperatures $\left(T_{m}\right)$ are shown and correspond to the bands in Fig. 1. We have used an asterix $\left(^{*}\right)$ to denote a positive band of correct size on the gel that also had positive melt curves and $T_{m}$ values as shown in this figure.

Additional file 7: Figure S6. Full size, unedited gels used for Fig. 2 in the main text. (A) MIR941-Male 1, (B) Rabbit $\beta$-globin fragment - Male 1 (C) MIR941-Male 2, (D) Rabbit $\beta$-globin fragment - Male 2, (E) MIR941Male 3, (F) Rabbit $\beta$-globin fragment - Male 3.

Additional file 8: Figure S7. Representative full panel of melt curves for Week 8, Male 1 showing MIR941 LNA qPCR. Positive (black writing) and negative (red writing) melt curves and associated melting temperatures $\left(T_{m}\right)$ are shown and correspond to the bands in Fig. 2. We have used an asterix $\left(^{*}\right)$ to denote a positive band of correct size on the gel that also had positive melt curves and $T_{m}$ values as shown in this figure.

Additional file 9: Figure S8. Full size, unedited gels used for Fig. 4 in the main text. (A) MIR941-Male 1, (B) Rabbit $\beta$-globin fragment - Male 1, (C) MIR941-Male 2, (D) Rabbit $\beta$-globin fragment - Male 2, (E) MIR941Male 3, (F) Rabbit $\beta$-globin fragment - Male 3, (G) MIR941-Male 4, (H) Rabbit $\beta$-globin fragment - Male 4, (I) MIR941-Male 5, (J) Rabbit $\beta$-globin fragment - Male 5 .

Additional file 10: Figure S9. Cropped (A) figures showing LNA qPCR products for MIR941 (top panel) and rabbit $\beta$-globin fragment (bottom panel) from a series of microcentrifuge and ultracentrifuge spins to isolate 
various fractions of whole blood in five 16 week treated male mice and one age-matched control and mock-treated male. Spins were (1) $3000 x$ g, (2) $12,000 \times g$ and (3) $110,000 \times g$. Full size, unedited gels are shown in (B) MIR941 and (C) rabbit $\beta$-globin fragment.

Additional file 11: Figure S10. Higher overall expression of MIR941 expression in the injected sites of 8 week animals compared to both 2 and 16 weeks. A UniSp6 spike-in control was used to normalize expression.

\section{Acknowledgements}

We thank D. McNeilly for his technical expertise and animal handling.

\section{Authors' contributions}

G.B. and P.A.B. conceived the study. G.B. acquired funding and designed the research. K.S.E. performed the stereotactic injections and dissections. E.A.B. performed dissections, all DNA/RNA extractions and all molecular analysis. G.B., P.A.B. and B.W.D. contributed resources. E.A.B. and G.B. wrote the manuscript, all other authors contributing to revision of the manuscript. G.B. supervised and provided oversight for the project. All authors read and approved the final manuscript.

\section{Funding}

This work was supported by a John Templeton Foundation Grant ID 60648

\section{Availability of data and materials}

All required data is included in the manuscript, Additional Files or Reference list.

\section{Ethics approval and consent to participate}

All animal procedures were approved by the QIMRB Animal Ethics committee, ethics \#A1612-622 M

\section{Competing interests}

The authors declare that they have no competing interests.

\section{Author details}

'QIMR Berghofer Medical Research Institute, Herston, QLD 4006, Australia. ${ }^{2}$ Fred Hutchison Cancer Research Center, Seattle, WA 98109, USA. ${ }^{3}$ Garvan Institute of Medical Research, Darlinghurst, NSW 2010, Australia. ${ }^{4}$ St Vincent's Clinical School, UNSW Sydney, Sydney, NSW 2052, Australia. ${ }^{5}$ Faculty of Medicine, UNSW Sydney, Sydney, New South Wales, Australia. ${ }^{6}$ The School of Biomedical Sciences, The University of Queensland, Brisbane, QLD 4072 Australia.

\section{Received: 26 December 2019 Accepted: 13 April 2020}

Published online: 30 April 2020

\section{References}

1. Carone BR, Fauquier L, Habib N, Shea JM, Hart CE, Li R, Bock C, Li C, Gu H, Zamore PD. Paternally induced transgenerational environmental reprogramming of metabolic gene expression in mammals. Cell. 2010;143: 1084-96.

2. Yeaman S, Hodgins KA, Lotterhos KE, Suren H, Nadeau S, Degner JC, Nurkowski KA, Smets P, Wang T, Gray LK. Convergent local adaptation to climate in distantly related conifers. Science. 2016;353:1431-3.

3. Klosin A, Casas E, Hidalgo-Carcedo C, Vavouri T, Lehner B. Transgenerational transmission of environmental information in C. elegans. Science. 2017;356: 320-3.

4. Singh DP, Saudemont B, Guglielmi G, Arnaiz O, Goût J-F, Prajer M, Potekhin A, Przybòs E, Aubusson-Fleury A, Bhullar S. Genome-defence small RNAs exapted for epigenetic mating-type inheritance. Nature. 2014;509:447.

5. Öst A, Lempradl A, Casas E, Weigert M, Tiko T, Deniz M, Pantano L, Boenisch U, Itskov PM, Stoeckius M. Paternal diet defines offspring chromatin state and intergenerational obesity. Cell. 2014;159:1352-64.

6. Warner DA, Uller T, Shine R. Transgenerational sex determination: the embryonic environment experienced by a male affects offspring sex ratio. Sci Rep. 2013;3:2709.

7. Bräutigam K, Vining KJ, Lafon-Placette C, Fossdal CG, Mirouze M, Marcos JG, Fluch S, Fraga MF, Guevara MÁ, Abarca D. Epigenetic regulation of adaptive responses of forest tree species to the environment. Ecol Evol. 2013;3:399_ 415.

8. Dias BG, Ressler KJ. Parental olfactory experience influences behavior and neural structure in subsequent generations. Nat Neurosci. 2014;17:89.

9. Rechavi O, Houri-Ze'evi L, Anava S, Goh WS, Kerk SY, Hannon GJ, Hobert O. Starvation-induced transgenerational inheritance of small RNAs in C elegans. Cell. 2014;158:277-87.

10. Bošković A, Rando OJ. Transgenerational epigenetic inheritance. Annu Rev Genet. 2018;52:21-41.

11. Miska EA, Ferguson-Smith AC. Transgenerational inheritance: models and mechanisms of non-DNA sequence-based inheritance. Science. 2016;354: 59-63.

12. Waldron D. Small RNAs: regulating transgenerational epigenetics. Nat Rev Genet. 2016;17:315.

13. Posner R, Toker IA, Antonova O, Star E, Anava S, Azmon E, Hendricks M, Bracha S, Gingold H, Rechavi O. Neuronal small RNAs control behavior transgenerationally. Cell. 2019;177:1814-26 e1815.

14. Gapp K, Jawaid A, Sarkies P, Bohacek J, Pelczar P, Prados J, Farinelli L, Miska E, Mansuy IM. Implication of sperm RNAs in transgenerational inheritance of the effects of early trauma in mice. Nat Neurosci. 2014;17:667-9.

15. Benito E, Kerimoglu C, Ramachandran B, Pena-Centeno T, Jain G, Stilling RM, Islam MR, Capece V, Zhou Q, Edbauer D, et al. RNA-dependent intergenerational inheritance of enhanced synaptic plasticity after environmental enrichment. Cell Rep. 2018;23:546-54.

16. Zhang Y, Shi J, Rassoulzadegan M, Tuorto F, Chen Q. Sperm RNA code programmes the metabolic health of offspring. Nat Rev Endocrinol. 2019;15: 489-98.

17. Houri-Ze'evi L, Korem Y, Sheftel H, Faigenbloom L, Toker IA, Dagan Y, Awad $L$, Degani $L$, Alon U, Rechavi O. A tunable mechanism determines the duration of the transgenerational small RNA inheritance in C. elegans. Cell. 2016;165:88-99.

18. Lasser C, Eldh M, Lotvall J. Isolation and characterization of RNA-containing exosomes. J Vis Exp. 2012(59):e3037. https://doi.org/10.3791/3037.

19. Cai Q, Qiao L, Wang M, He B, Lin FM, Palmquist J, Huang SD, Jin H. Plants send small RNAs in extracellular vesicles to fungal pathogen to silence virulence genes. Science. 2018;360:1126-9.

20. Thomou T, Mori MA, Dreyfuss JM, Konishi M, Sakaguchi M, Wolfrum C, Rao TN, Winnay JN, Garcia-Martin R, Grinspoon SK, et al. Adipose-derived circulating miRNAs regulate gene expression in other tissues. Nature. 2017; 542:450-5.

21. Guduric-Fuchs J, O'Connor A, Camp B, O'Neill CL, Medina RJ, Simpson DA. Selective extracellular vesicle-mediated export of an overlapping set of microRNAs from multiple cell types. BMC Genomics. 2012;13:357.

22. Skinner MK, Ben Maamar M, Sadler-Riggleman I, Beck D, Nilsson E, McBirney M, Klukovich R, Xie Y, Tang C, Yan W. Alterations in sperm DNA methylation, non-coding RNA and histone retention associate with DDT-induced epigenetic transgenerational inheritance of disease. Epigenetics Chromatin. 2018;11:8.

23. Ben Maamar M, Sadler-Riggleman I, Beck D, McBirney M, Nilsson E, Klukovich R, Xie Y, Tang C, Yan W, Skinner MK. Alterations in sperm DNA methylation, non-coding RNA expression, and histone retention mediate vinclozolin-induced epigenetic transgenerational inheritance of disease. Environ Epigenet. 2018:4:dvy010.

24. Sarangdhar MA, Chaubey D, Srikakulam N, Pillai B. Parentally inherited long non-coding RNA Cyrano is involved in zebrafish neurodevelopment. Nucleic Acids Res. 2018;46:9726-35.

25. An T, Zhang T, Teng F, Zuo JC, Pan YY, Liu YF, Miao JN, Gu YJ, Yu N, Zhao $D D$, et al. Long non-coding RNAs could act as vectors for paternal heredity of high fat diet-induced obesity. Oncotarget. 2017:8:47876-89.

26. Soumillon M, Necsulea A, Weier M, Brawand D, Zhang X, Gu H, Barthes P, Kokkinaki M, Nef S, Gnirke A, et al. Cellular source and mechanisms of high transcriptome complexity in the mammalian testis. Cell Rep. 2013;3:2179-90.

27. Hu HY, He L, Fominykh K, Yan Z, Guo S, Zhang X, Taylor MS, Tang L, Li J, Liu $J$, et al. Evolution of the human-specific microRNA miR-941. Nat Commun. 2012;3:1145

28. Foust KD, Nurre E, Montgomery CL, Hernandez A, Chan CM, Kaspar BK. Intravascular AAV9 preferentially targets neonatal neurons and adult astrocytes. Nat Biotechnol. 2009;27:59-65.

29. Hammond SL, Leek AN, Richman EH, Tjalkens RB. Cellular selectivity of AAV serotypes for gene delivery in neurons and astrocytes by neonatal intracerebroventricular injection. PLoS One. 2017;12:e0188830. 
30. Hutson TH, Kathe C, Moon LD. Trans-neuronal transduction of spinal neurons following cortical injection and anterograde axonal transport of a bicistronic AAV1 vector. Gene Ther. 2016;23:231-6.

31. Xiao L, Bornmann C, Hatstatt-Burkle L, Scheiffele P. Regulation of striatal cells and goal-directed behavior by cerebellar outputs. Nat Commun. 2018; 9:3133.

32. Hong BS, Cho JH, Kim H, Choi EJ, Rho S, Kim J, Kim JH, Choi DS, Kim YK, Hwang D, Gho YS. Colorectal cancer cell-derived microvesicles are enriched in cell cycle-related mRNAs that promote proliferation of endothelial cells. BMC Genomics. 2009;10:556.

33. Zhou R, Chen KK, Zhang J, Xiao B, Huang Z, Ju C, Sun J, Zhang F, Lv XB, Huang $G$. The decade of exosomal long RNA species: an emerging cancer antagonist. Mol Cancer. 2018;17:75.

\section{Publisher's Note}

Springer Nature remains neutral with regard to jurisdictional claims in published maps and institutional affiliations.

Ready to submit your research? Choose BMC and benefit from:

- fast, convenient online submission

- thorough peer review by experienced researchers in your field

- rapid publication on acceptance

- support for research data, including large and complex data types

- gold Open Access which fosters wider collaboration and increased citations

- maximum visibility for your research: over $100 \mathrm{M}$ website views per year

At BMC, research is always in progress.

Learn more biomedcentral.com/submissions 